\title{
Influence of the electric voltage gradient, electrode spacing and electrode radius on slurry dewatering by vertical electro-osmosis
}

\author{
Liang Wen, Changhong Yan* \\ School of Earth Sciences and Engineering, Nanjing University, Nanjing 210093, China \\ "E-mail: yanchh@nju.edu.cn \\ doi: $10.20964 / 2020.11 .13$
}

Received: 22 June 2020 / Accepted: 17 August 2020 / Published: 30 September 2020

\begin{abstract}
Electro-osmosis technology is an effective method for slurry dewatering, and the voltage gradient, electrode spacing and electrode radius have a large effect on electro-osmosis dewatering. In this paper, a series of tests are conducted to study the effects of those factors on slurry dewatering. The results indicate that a higher voltage gradient can improve electro-osmosis dewatering. Under the same voltage gradient, a smaller electrode spacing leads to a lower discharge rate and less energy consumption, but the water content is also smaller than that with a larger electrode spacing. A larger electrode radius has a good effect on electro-osmosis dewatering, but its energy consumption is also increased. When the slurry is dewatered by electro-osmosis, the water content will be maldistributed after dewatering, with the lowest water content in the anode and the highest in the cathode, and the factors that affect electroosmosis are also analyzed theoretically. In engineering applications, the voltage gradient and electrode radius should be increased appropriately, and the electrode spacing should be reduced to obtain a lower water content.
\end{abstract}

Keywords: Electro-osmosis dewatering; Voltage gradient; Electrode spacing; Electrode radius;

\section{$\underline{\text { FULL TEXT }}$}

(C) 2020 The Authors. Published by ESG (www.electrochemsci.org). This article is an open access article distributed under the terms and conditions of the Creative Commons Attribution license (http://creativecommons.org/licenses/by/4.0/). 